\title{
Reliability analysis for seismic capacity of casing strings
}

\author{
Jinwei Gao ${ }^{1} \cdot$ Wen Shi $^{1} \cdot$ Shaohua Cui ${ }^{2} \cdot$ Yongfeng Jiao $^{1}$ \\ Received: 25 March 2019 / Accepted: 18 August 2019 / Published online: 23 August 2019 \\ (c) The Author(s) 2019
}

\begin{abstract}
Based on the analysis of seismic intensity and randomness, an earthquake intensity probability model is built, and the relationship between seismic intensity and seismic acceleration is presented. The distribution law of casing parameters, including outer diameter, wall thickness, Young's modulus and Poisson's ratio, is described by analyzing the randomness of casing geometry and mechanical properties. With the setting up a mechanical model of the casing strings in earthquakes, and using the spectral modal analysis theory and the equivalent static load method, the calculation method of the equivalent load of casing strings under seismic action is studied. The limit state equations of various failure forms of casing strings in earthquakes are established. Based on the theory of structural reliability, the reliability model of casing strings under seismic action is built. The seismic reliability of casing strings is calculated, and the calculation results are verified by field data. The calculation results show that influence of earthquake on safety and reliability of casing strings is very serious for long service life oil and gas wells in areas where the seismic fortification intensity is high.
\end{abstract}

Keywords Casing strings $\cdot$ Seismic $\cdot$ Randomness $\cdot$ Structural reliability

\section{Introduction}

Casings play an important role in oil and gas production. With the passage of time, the possibility of casings failure increases, which has become an important factor restricting the sustainable development of many oil and gas fields in China and other places of the world.

Earthquake is one important cause for casings failure (Xu 1992). However, there have been little researches on the reaction of casing strings under seismic action by so far. In long service life oil and gas wells, the randomness of seismic action, and the randomness of pipe geometry and mechanical properties will be not negligible, and their influences on casings failure will also be not negligible. Therefore, seismic reliability evaluation is of important engineering value.

Wen Shi

415533927@qq.com

1 China Petroleum Technology and Development Corporation, Beijing 100028, China

2 Petrochina Pipeline Company Ltd, Beijing 100029, China

\section{Seismic intensity and randomness}

Earthquake intensity and probability of occurrence are two basic parameters for an earthquake. The former is specified by the term of seismic intensity, while the latter is described by the seismic randomness. The seismic intensity and randomness have a strong correlation.

\section{Earthquake intensity probabilistic model}

The stochastic probability distribution function of seismic intensity is subject to the law of extremum III distribution, as follows (Gao and Bao 1985):

$F_{t}(I)=\left[f_{T}(I)\right]^{\frac{t}{T}}=\exp \left[-\frac{t}{T}\left(\frac{12-I}{12-I_{s}}\right)^{K}\right]$

Mean and variance is as follows (Dai and Wang 1987):

$\mu_{I}=12-\left(12-I_{s}\right) \Gamma(1+1 / K)$

$\sigma_{I}=\left(12-I_{s}\right) \sqrt{\Gamma(1+2 / K)-\Gamma^{2}(1+1 / K)}$

where $t$ stands for time, a (years); $T$ for base period, $T=50 \mathrm{a}$; $I$ for seismic intensity, $I=1,2,3, \ldots, 12$; and $I_{s}$ stands for seismic portrait intensity (Chen et al. 2016), which means the

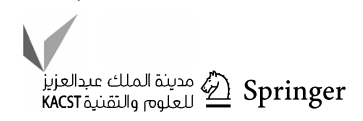


seismic intensity with exceeding possibility of $63.2 \%$ within $50 \mathrm{a}, I_{s}=I_{0}-1.55 ; I_{0}$ stands for seismic fortification intensity. Seismic fortification intensity means the seismic intensity which is regarded as the basis of seismic fortification in a region according to relevant national regulations (Architecture Design Handbook Editorial Board 1994); $K$ stands for shape factor.

Distribution parameters of each fortification intensity level in accordance with the literature (Gao and Bao 1985) are shown in Table 1.

For a better understanding about the relationship between fortification intensity and actual earthquake possibility, this paper gives the actual earthquake possibility in areas of different fortification intensity levels in 20 years, as is shown in Table 2 .

It can be concluded that seismic fortification intensity is safe enough as a design basis (Tao et al. 2018). For example, for areas of fortification intensity of 6 , the occurrence possibility of magnitude- 6 earthquake is only $4.1268 \%$, while the occurrence possibility of magnitude- 7 earthquake is only $0.7 \%$. In following discussion of this paper, seismic fortification intensity will be adopted as the design and calculation basis.

\section{The acceleration description of earthquake intensity}

Seismic acceleration is used to describe the ground motion acceleration in earthquake. There is correspondence between seismic acceleration and seismic intensity which can be represented by fortification intensity. And among the acceleration in three directions, one of the accelerations in the horizontal direction is the maximum (Construction Department of P.R.C. 2001; Wu et al. 2002), so maximal horizontal acceleration is adopted as the design base seismic acceleration. According to Chinese National Construction Earthquake Fortification Criteria, the design value of maximal horizontal acceleration shall follow Table 3.

The conversion relation between earthquake intensity and maximal horizontal acceleration is also presented in the literature (Wu et al. 2002) according to theory of Liu et al. (1981), shown as follows:

$A_{\mathrm{I} H}=0.81 \times 2^{I}$

Table 1 Seismic intensity distribution parameters

\begin{tabular}{lllll}
\hline $\begin{array}{l}\text { Seismic } \\
\text { fortification } \\
\text { intensity } I_{0}\end{array}$ & $\begin{array}{l}\text { Shape fac- } \\
\text { tor } K\end{array}$ & $\begin{array}{l}\text { Equaliz- } \\
\text { ing value } \\
\mu_{I}\end{array}$ & $\begin{array}{l}\text { Standard } \\
\text { deviation } \\
\sigma_{I}\end{array}$ & $\begin{array}{l}\text { Coefficient of } \\
\text { variation } C_{I}\end{array}$ \\
\hline 6 & 9.7933 & 4.8237 & 0.8806 & 0.1826 \\
7 & 8.3339 & 5.8195 & 0.8826 & 0.1517 \\
8 & 6.8714 & 6.8133 & 0.8866 & 0.1301 \\
9 & 5.4029 & 7.8037 & 0.8954 & 0.1147 \\
\hline
\end{tabular}

Table 2 Possibility of earthquake in areas with different seismic fortification intensity levels

\begin{tabular}{lccrl}
\hline $\begin{array}{l}\text { Seismic fortifica- } \\
\text { tion intensity } I_{0}\end{array}$ & \multicolumn{4}{l}{ Magnitude } \\
\cline { 2 - 5 } & $6(\%)$ & $7(\%)$ & $8(\%)$ & $9(\%)$ \\
\hline 6 & 4.1268 & 0.7043 & 0.0794 & 0.0047 \\
7 & 17.5175 & $4.1268 \$$ & 0.6541 & 0.0597 \\
8 & 49.5133 & 17.7385 & 4.1267 & 0.5820 \\
9 & 83.1875 & 48.6147 & 18.0791 & 4.128 \\
\hline
\end{tabular}

where $A_{I H}$ is the maximal horizontal acceleration at seismic intensity $I, \mathrm{~cm} \mathrm{~s}^{-2}$. The calculation results are in accordance with Table 3.

Furthermore, the maximal vertical acceleration value is between $1 / 2$ and $2 / 3$ of the maximal horizontal acceleration value. $1 / 2$ is used as the coefficient in the calculation of maximal vertical acceleration calculation.

$A_{I V}=0.5 A_{\mathrm{I} H}=0.41 \times 2^{I}$

$A_{I V}$ is the maximal vertical acceleration at seismic intensity of $I, \mathrm{~cm} \mathrm{~s}^{-2}$.

\section{Randomness of casing dimension and mechanical parameters}

The factors affecting the strength of the casing are mainly the physical dimensions and mechanical properties of the casing, including the outer diameter, wall thickness, elastic modulus and Poisson's ratio of the casings. According to the statistical test of 2000 joints of API casings from five manufacturers (Adams et al. 1993), combined with the research of Galambos and Ravindra (1978), it is found that the above parameters are in accordance with the normal distribution, as is illustrated in Eq. 6, and the corresponding distribution parameters are shown in Table 4:

$f(x)=\frac{1}{\sqrt{2 \pi} \sigma_{x}} \exp \left[-\frac{\left(x-\mu_{x}\right)^{2}}{2 \sigma_{x}^{2}}\right]$

where $x$ stands for random variables, which generally refers to actual physical dimension and mechanical property; $\mu_{x}$ stands for mean value of random variable; $\sigma_{x}$ stands for standard deviation of random variables.

Table 3 Maximal horizontal acceleration at difference intensity

\begin{tabular}{lrrrrr}
\hline Seismic fortification intensity & 6 & 7 & 8 & 9 & 10 \\
Horizontal acceleration cm/s & 50 & 100 & 200 & 400 & 800 \\
\hline
\end{tabular}


Table 4 Mean values and variation coefficients of casing parameters

\begin{tabular}{llllll}
\hline Parameters & $\begin{array}{l}\text { Casing' out- } \\
\text { side diameter } \\
(D)\end{array}$ & Wall thickness $(t)$ & $\begin{array}{l}\text { Yield } \\
\text { strength } \\
\left(Y_{\mathrm{P}}\right)\end{array}$ & $\begin{array}{l}\text { Elastic } \\
\text { modulus } \\
(E)\end{array}$ & Poisson's ratio $(v)$ \\
\hline Mean value/nominal value & 1.005 & 1.00 & 1.09 & 1.00 & 1.00 \\
Variation coefficient & 0.0013 & 0.018 & 0.022 & 0.035 & 0.025 \\
\hline
\end{tabular}

\section{Casing reaction calculation in earthquakes}

\section{The mechanical model of casing strings in earthquakes}

Since the axial dimension of the casing strings is much larger than the radial dimension, the casing string is regarded as a continuous structure. The casing head structure is negligible (Xue et al. 2000). The casing string is an axisymmetric structure, so it can be considered that the seismic impact does not apply torques on the casing strings. Due to the low gas density and low viscous drag, the effect of gas in the casings is negligible for gas wells. And because of the low flow rate in the casings of the oil wells, it can also be considered that the fluid influence in the casings of oil wells is negligible. There is the cementing force and friction between the cement rings and the casings, and these forces dampen the vibration of the casings. Meanwhile, taking into account the linear elastic properties of the cement rings and the adjacent formation rock within a certain range, the constraints of the cement rings and the formation rock on the casings can be simplified to an elastic-damping constraint. Since the seismic acceleration generally consists of acceleration in three directions - two horizontal directions and one vertical direction, there are three orthogonal seismic loads on casing strings in this mechanical model.

The casing strings mechanical model in earthquakes is shown in Fig. 1, where $K_{A}$ and $K_{T}$ stand for axial and transverse elastic stiffness of the constraint, and $C_{A}$ and $C_{T}$ stand for axial and transverse damping coefficients, respectively. It is obvious that the model is multi-particle and multi-degree of freedom model.

\section{Calculation of casing strings equivalent stress in earthquakes}

For the response of casing strings in earthquake, the most concerned issue shall be its maximum dynamic response, especially the maximum stress of casing strings caused by earthquakes.

For the vibrational mechanical model of casing strings with multiple degrees of freedom, the equivalent static stress calculation of casing strings under seismic action can be carried out according to the spectral modal analysis theory and seismic equivalent static load (Shen et al. 2000).

The $j$ th order force exerted by earthquakes on casing strings structure can be expressed as:

$\{F\}_{j}=[M]\{\Phi\}_{j} \gamma_{j} A_{a}\left(\omega_{j}, C_{j}, \xi_{j}\right) \quad j=1,2, \ldots, N$

where $\{F\}_{j}$ stands for the $j$ th order force of the maximal vibration mode; $[M]$ stands for mass matrix of casing strings structure; $\{\Phi\}_{j}$ stands for the $j$ th order vibration of the casing strings structure; $\gamma_{j}$ stands for the $j$ th order mode participation coefficient; $\omega_{j}$ stands for the $j$ th order of natural frequency of the casing strings; $C_{j}$ stands for the $j$ th order elastic stiffness coefficient of casing constraint, corresponding with $K_{A}$ and $K_{T}$ in Fig. $1 ; \xi_{j}$ stands for the $j$ th damping of casing constraint; $A_{a}\left(\omega_{j}, C_{j}, \xi_{j}\right)$ stands for the $j$ th seismic acceleration response spectrum. The calculation of acceleration response spectrum and its parameters is detailed as follows (Fu 1990):

$A_{a}\left(\omega_{j}, C_{j}, \xi_{j}\right)=A(\omega)\left[H\left(\omega_{j}, C_{j}, \xi_{j}\right)\right]$

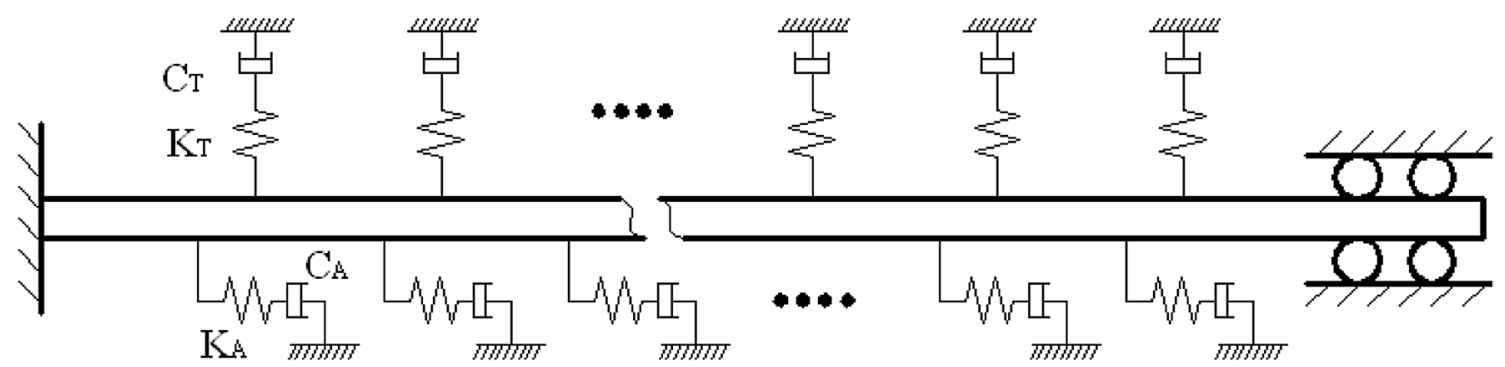

Fig. 1 Casing strings mechanical model in earthquakes 
where $\left[H\left(\omega_{j}, C_{j}, \xi_{j}\right)\right]$ stands for the $j$ th order transfer function array of casing strings structure; $A(\omega)$ stands for the seismic acceleration $j$ th order response spectrum. The calculations of natural frequency, mode of vibration, mode of vibration participation coefficient and transfer function array have been introduced by many studies (Gao et al. 1995; Shuai et al. 1999).

Seismic response stress of various modes in the casing strings $\{S\}_{j}$ and corresponding equivalent stress $S$ can be calculated by statics methods:

$[K]\{S\}_{j}=\{F\}_{j}$

$S=\sqrt{\sum_{i=1}^{N} \sum_{j=1}^{N} \rho_{o, i j} S_{i} S_{j}}$

where $[K]$ stands for stiffness matrix of casing strings structure; $S, S_{i}$ and $S_{j}$ stand for components of $\{S\},\{S\}_{i}$ and $\{S\}_{j}$ respectively; $\rho_{o i j}$ stands for mode of vibration cross-correlation function. Proximate solution is as follows (Shen et al. 2000):

$\rho_{o, i j}=\frac{8\left(\omega_{i} \xi_{i}+\omega_{j} \xi_{j}\right)\left(\omega_{i} \omega_{j}\right)^{3 / 2}\left(\xi_{i} \xi_{j}\right)^{1 / 2}}{2\left(\omega_{i} \xi_{i}+\omega_{j} \xi_{j}\right)^{2}\left(\omega_{i}^{2}+\omega_{j}^{2}\right)+\left(\omega_{i}^{2}-\omega_{j}^{2}\right)}$

The casing maximal axial load, transverse load and equivalent stress in earthquake effect can be solved by this method.

\section{Seismic reliability evaluation of casing strings}

\section{The reliability model of casing strings under seismic action}

Under seismic action, the failure modes of the casing include strength failure, axial elastic instability and lateral deformation (He et al. 2018). The limit state equations are as follows.

1. The casing strings strength failure.

$$
Z_{S}=Y_{P}-S=0
$$

2. The casing strings axial elastic instability.

$$
Z_{A}=F_{L J}-F_{A Y}=0
$$

3. The casing strings lateral deformation.

$Z_{f}=f_{\text {lim }}-f=0$

where $Y_{P}$ stands for casing yield strength, MPa; $F_{L J}$ stands for the critical load of the casing strings axial elastic instability, $\mathrm{KN} ; F_{A Y}$ stands for the actual axial load of the casing strings, $\mathrm{KN} ; f_{\text {lim }}$ stands for casing strings allowable lateral deformation $\mathrm{mm} ; f$ stands for the actual lateral deformation of the casing strings, $\mathrm{mm}$.

Based on seismic fortification intensity for the region, the probability of failure in multiple forms of casing strings in earthquakes within 1 year can be expressed as:

$P_{f n}=\underset{j=1}{12}\left\{P_{f n}^{I_{j}}\left(Z_{n}<0\right) \cdot P_{t}\left(I_{j}\right)\right\}$

where $P_{f n}$ stands for casing strings failure probability in the form of $n ; P_{f n}^{I_{j}}\left(Z_{n}<0\right)$ stands for casing strings failure probability in the form of $n$ in earthquake of magnitude $j ; Z_{n}$ generally refers to $Z_{S}, Z_{A}$ and $Z_{f}$ in formulation (12) to (14), standing for casing strings failure form; $P_{t}\left(I_{j}\right)$ stands for the occurrence probability of earthquakes exceeding magnitude $I_{j}$ during $t$ years; $M A X\{\bullet\}$ stands for max function.

Since the casing strings are a typical series system, the casing strings will fail as long as one failure form occurs. The overall reliability of the casing strings during its service life is as follows (Liu 1996).

$R=\prod_{n=1}^{3}\left(1-P_{f n}\right)$

\section{Calculation example of casing string seismic reliability}

The length of a production casing is $3000 \mathrm{~m}$, the material is $\mathrm{N}-80$, the outer diameter is $177.8 \mathrm{~mm}$, and the wall thickness is $13.7 \mathrm{~mm}$. The elastic modulus of cement ring and formation rock is $20 \mathrm{Gpa}$, and there is strong binding force between the two layers. The designed service life of oil well is 20 years. The seismic fortification intensity is 7. According to Housner and Jennings's advice (1964), the seismic acceleration frequency for hard ground conditions is $15.6 \mathrm{~Hz}$, and the damping is 0.64 . In this paper, the seismic acceleration frequency will be changed in the range of 0.1-20 Hz.

In the service life of the casing string, the failure probability in earthquakes of different magnitudes is calculated, and the results are shown in Table 5.

It can be seen from Table 5 that the overall seismic reliability of the casing strings is $99.19 \%$. When the magnitude is below 6 , the casing string has high reliability and the multiform failure probability is low. When earthquake intensity is magnitude 9 or above, the casing string is almost destroyed. However, the low fortification intensity in this area indicates that the probability of a high-intensity earthquake is very low. Generally, the casing string still has high reliability and can meet the seismic requirements. 
Table 5 Casing string failure probability in earthquakes of different magnitudes during service life (\%)

\begin{tabular}{llrrrr}
\hline Casing failure form & \multicolumn{2}{l}{ Magnitude } & \multicolumn{2}{c}{$\begin{array}{c}\text { Failure probability } \\
\text { in the service life }\end{array}$} \\
\cline { 2 - 5 } & 6 & \multicolumn{1}{c}{7} & \multicolumn{1}{c}{8} & 9 & \\
\hline a. Strength Failure & $9.12 \times 10^{-2}$ & 10.33 & 39.07 & 87.59 & 0.43 \\
b. Axial Elastic Instability & $3.27 \times 10^{-4}$ & 3.70 & 42.35 & 94.94 & 0.03 \\
c. Lateral deformation & 0.17 & 8.47 & 50.01 & 99.96 & 0.35 \\
Overall seismic reliability & 99.74 & 79.04 & 17.56 & $<0.01$ & 99.19 \\
\hline
\end{tabular}

\section{Field data verification}

There are very few statistical data of casing failure cases caused by earthquakes in the literature and reports. This paper analyzes one case data obtained after Wenchuan earthquake.

On May 12th, 2008, a magnitude 8.0 earthquake occurred in Wenchuan, Sichuan Province of China, causing nearly 80,000 deaths and huge property losses. In Sinopec Puguang Gas Field which is located in the seismic zone, some gas wells were found to have casing failure of varying degrees. Sinopec used caliper logging tool to detect casing failure in Puguang gas field. A total of 22 wells were checked, and casing failure was found in 20 wells (Ge et al. 2010). In this case, the ratio of casing failure wells to statistical wells shows that the seismic failure rate of casing in Wenchuan M8.0 earthquake is $90.9 \%$, which is relatively close to the calculated failure possibility of $82.44 \%$ according to Table 5 .

\section{Conclusions}

In addition to the traditional calculation method for casing strength, this paper fully considers the randomness of earthquakes, as well as randomness of casing physical dimensions and mechanical properties. In order to analyze the load on the casing strings in earthquakes, a seismic reliability analysis for the casing strings of oil and gas wells based on reliability theory is carried out. And the conclusions are as below.

1. The occurrence possibility of failure inducing factors and corresponding probability of leading to failure should be comprehensively calculated in casing strings reliability analysis.

2. Other than traditional nominal strength and safety factor calculation, reliability theory is introduced into the seismic resistance analysis of casings. The seismic randomness and casing resistance are taken into consideration in the strength design. A more reasonable seismic reliability analysis method is established.

3. A sample calculation is carried out based on the proposed seismic reliability analysis method. Compared with the data of casing failure in Puguang gas field after
Wenchuan earthquake, the reliability of the calculation model is verified.

4. Though the casing strings are generally reliable in areas with low seismic fortification intensity, the seismic influence should still be seriously considered in the casing strings designing for long service life oil and gas wells, especially in areas with high seismic fortification intensity.

Open Access This article is distributed under the terms of the Creative Commons Attribution 4.0 International License (http://creativeco mmons.org/licenses/by/4.0/), which permits unrestricted use, distribution, and reproduction in any medium, provided you give appropriate credit to the original author(s) and the source, provide a link to the Creative Commons license, and indicate if changes were made.

\section{References}

Adams AJ, Parfitt S, Reeves T et al (1993) Casing system risk analysis using structural reliability. SPE/IADC 25693:169-178. https:// doi.org/10.2118/25693-MS

Architecture Design Handbook Editorial Board (1994) Construction aseismic. Beijing, China

Chen A, Yang Y, Ma R (2016) risk-based design method of disaster-resistance performance for bridge. J Tongji Univ Nat Sci 44:103-109

Construction Department of P.R.C (2001) GB50011-2001: construction earthquake resistant design code. Beijing, China

Dai S, Wang M (1987) Reliability engineering and application in the chemical processing equipment. Beijing, China, pp 30-31

Fu Z (1990) Vibration modal analysis and parameter identification. Beijing, China, pp 40-47

Galambos TV, Ravindra MK (1978) Properties of steel for use in LRFD. Proc J Struct Div ASCE 104:1459-1468

Gao X, Bao A (1985) Probabilistic model and statistical parameter of earthquake effect. Earthq Eng Eng Vib 1:13-22

Gao Z, Zhu J, Tang J et al (1995) Architecture aseismic design. Beijing, China, pp 67-79

Ge H, Shen C, Song L et al (2010) The influence of wenchuan earthquake on puguang gas field development. Eng Sci 10:103-107

He S, Lin H, Zhou L, Liu W, Chang J (2018) Comprehensive analysis the casing deformation in shale gas reservoir modification by seismic and microseismic. SEG 2018 Workshop: Reservoir Geophysics. https://doi.org/10.1190/REGE2018-33.1

Housner GW, Jennings PC (1964) Generation of artificial earthquakes. J Eng Mech Div ASCE 90:437-438

Liu W (1996) Mechanical reliability design. Beijing, China, pp 293-294

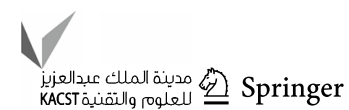


Liu H, Lu R, Chen D et al (1981) Revise a proposed projects of earthquake intensity. In: Earthquake engineering research reports (the fourth). Beijing, China, pp 1-13

Shen J, Zhou X, Gao X et al (2000) Earthquake engineering. Beijing, China, pp 97-105

Shuai J, Lv Y, Cai Q (1999) Underground oil pipeline stationary random vibration. Univ Pet J (Phys Sci Ed) 23:65-70

Tao X, Tao Z, Li D et al (2018) Seismic fortification intensity evaluation by a cost-benefits analysis - case study of three bridges. In: 2018 International Conference on Civil and Hydraulic Engineering (IConCHE 2018). https://doi.org/10.1088/1755$1315 / 189 / 5 / 052043$

Wu B, Ou J, Zhang J (2002) Structural impair performance design based on reliability. World Earthq Eng 18:10-18
Xu Y (1992) Analyses and prevention of production casing spoiled factors. Drilled Craft 15:63-68

Xue J, Cui D, Wang Z et al (2000) Underground oil pipeline dynamic response in the lateral earthquake effect. J Inst Daqing Pet 24:96-99

Publisher's Note Springer Nature remains neutral with regard to jurisdictional claims in published maps and institutional affiliations. 